\title{
NUMERICAL SOLUTION OF SOIL - FOUNDATION INTERACTION AND COMPARISON OF RESULTS WITH EXPERIMETAL MEASUREMENTS
}

\author{
Radim Cajka ${ }^{1}$, Jana Labudkova², Petr Mynarcik ${ }^{3}$ \\ 1,2,3 Faculty of Civil Engineering, VSB - Technical University Ostrava, Department of Structures, Ludvika \\ Podeste 1875/17, 70833 Ostrava - Poruba, Czech Republic
}

\begin{abstract}
Several experimental measurements of reinforced concrete slab - subsoil interaction are compared with numerical analysis of shallow foundation by means of FEM. At the Faculty of Civil Engineering VSB - Technical University of Ostrava testing device was constructed so that the phenomena of soil foundation interaction could be experimentally investigated and compared with numerical models. Results of experimental loading test are compared with soil - foundation interaction analysis based on finite element method (FEM). The purpose of this paper is to compare resulting deformation of the slab, subsidence of the subsoil, bending moments and contact stress calculated by different software based on FEM. Currently there are several software that, can deal with the interaction of foundations and subsoil.
\end{abstract}

Keywords: Foundation Structure, Experimental Measurement, Soil - Structure Interaction, Interaction Models, FEM Calculation.

\section{INTRODUCTION}

Analysis of the subsoil-structure interaction is influenced by physical and non-linear behaviour of the structure, by the interaction of the upper structure and foundation structure and by selecting of interaction model. Insufficient theoretical basics of the investigated issue and the absence of an appropriate calculation tools still hinder to unambiguous solution of subsoil-structure interaction. Analysis of this interaction task is also made more difficult by lower accuracy of input data. Lower accuracy of input data is associated with a description of the subsoil properties and subsoil behaviour. Subsoil is made up of heterogeneous particles. Uncertainties of description of subsoil behaviour are also associated with the complexity to describe the geological profile in detail [21, 22]. Using a combination of experimental measurements, laboratory tests and testing in-situ, modelling and numerical methods is optimal to obtain reliable results of interaction tasks. Such experimental measurements are performed in the Czech Republic and in the world, in past and also in present.

\section{EXPERIMENTAL LOADING TEST}

Interaction model of prestressed concrete foundation slab with the subsoil was solved using 3D numerical modelling in ANSYS 15.0. Input data of solved task were taken from experimental measurements ongoing during the loading test carried out with the experimental equipment. The testing equipment called Stand consists of two frames. Crossbeams enable variability of the press machine location. The frames are anchored with screws into the steel grate based in the reinforced concrete strip foundations. The construction is anchored with $4 \mathrm{~m}$ long micropiles. The highest possible vertical load is $1 \mathrm{MN}$. The experimental equipment is described with more details in [15]. Another experimental loading tests and their results are also described in [2, 3, 6, 7, 8, 11, 19].

The test sample of experimental loading test was post-tensioned concrete slab [5]. Post-tensioned concrete slab had the dimensions 2000x2000x150mm (Fig. 1). Concrete class C35/45 was used. Slab was post-tensioned by six threaded prestressing bars. The bars were from steel Y 1050 and their diameter was $18 \mathrm{~mm}$. Each rod was tensioned by force of $100 \mathrm{kN}$.

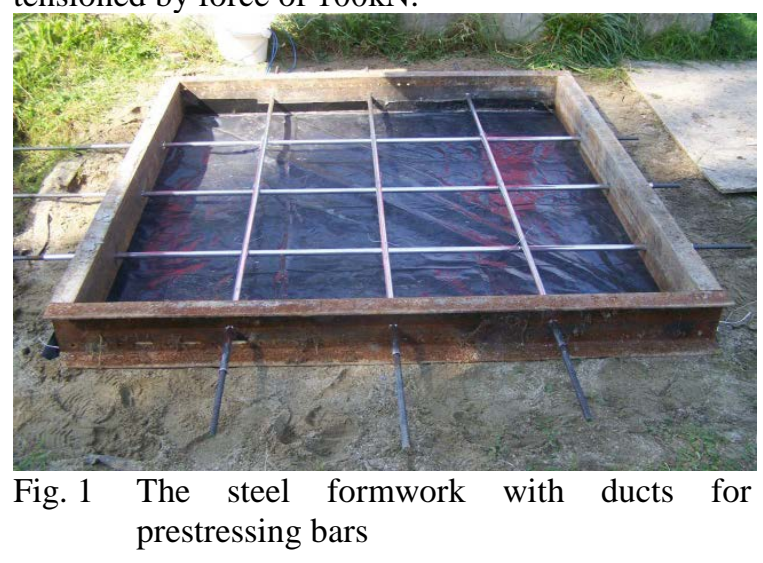

Thredbars were anchored by domed nuts and recessed anchor plates (Fig. 2). The model was laid on homogenous sand subsoil. The sliding joint was 
placed between contact surface of concrete floor model and sand subsoil.

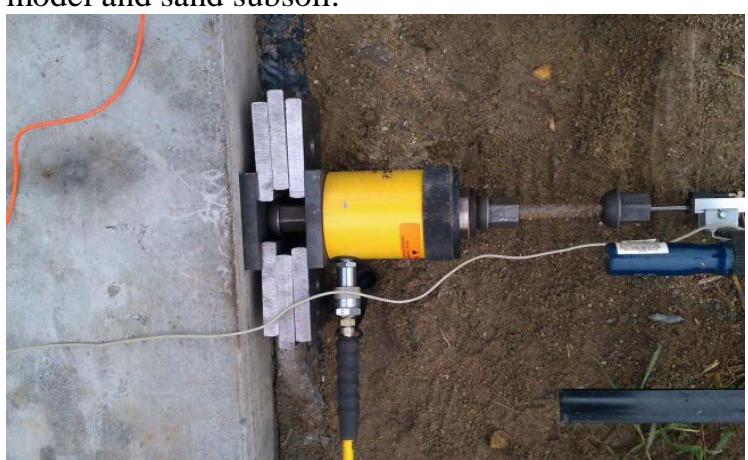

Fig. 2 The presstresing system

These are simple foundation conditions from a geological point of view. The $300 \mathrm{~mm}$ layer of clay soil was removed before loading test of posttensioned concrete slab. The footing bottom was filled with gravel fraction $0-4 \mathrm{~mm}$ to the edge of the surrounding terrain. The original subsoil composed of loess loam with consistency class F4 and with layer $5 \mathrm{~m}$ remained under a new gravel bed. Deformation characteristics thus composed subsoil were determined by geotechnical testing. Subsoil has been described by following characteristics Poisson coefficient $\mu=0.35$, modulus of deformability $\mathrm{E}_{\operatorname{def} 2}=33.86 \mathrm{MPa}$.

Post-tensioned concrete slab model was loaded in the middle of the slab by pressure exerted by the hydraulic press during the experimental loading test (Fig. 3). The dimensions of the loaded area were 200x200mm. Loading was carried out in parts, $75 \mathrm{kN} / 30 \mathrm{~min}$.

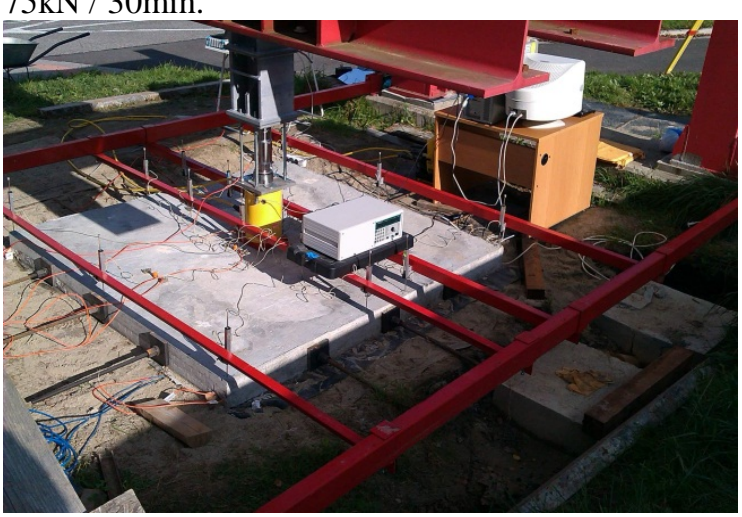

Fig. 3 Experimental loading test

14 potentiometric position sensors were used for measurement of vertical deformations (subsidence). Built-in pressure sensor was used for measurement of the vertical load. 4 strain gauges were used for measurement on the surface of the slab - tension of the concrete. 4 strain gauges were used for measurement inside the experimental slab - tension of the concrete. 3 geotechnical pressure cells were used for measurement of the stress on the interface of the slab and subsoil. 8 temperature sensors were used for measurement of temperature inside and on the surface.

The slab failed during the 7th cycle during this method of loading. Cracks on the lower surface of experimental post-tensioned slab after its broken you can see in the Fig. 4. The maximum level of load was $525 \mathrm{kN}$. The first significant cracks were detected after the 4th loading cycle. These cracks were located in the vicinity of the middle anchors of prestressing bars. The model of post-tensioned concrete foundation slab was violated by punching shear. Punching shear of slabs is discussed in detail [1].

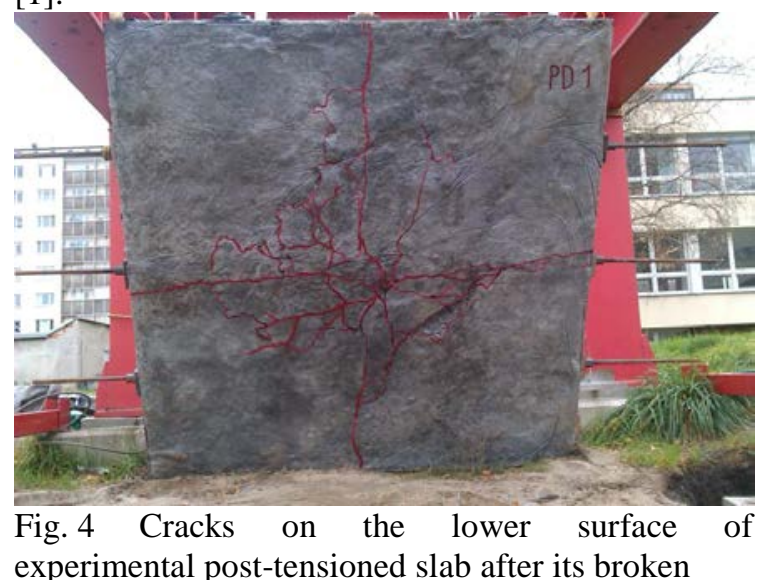

\section{THE SPATIAL NUMERICAL MODEL OF INHOMOGENEOUS HALF-SPACE}

3D subsoil model can be created as a half-space, ie. body bounded from above by plane. Half-space can be modelled discretely or as a continuum. The simplest idealization of the elastic half-space is homogeneous and isotropic body. Soil is heterogeneous material and its properties are different from idealization linear elastic, isotropic and homogeneous substance. Therefore, the calculated values of the settlement do not correspond with the real values - measured in real buildings or during the experiments $[9,10,17,18,20]$. Inhomogeneous half-space was used for the analysis of the interaction of loaded post-tensioned concrete slab with the subsoil. In inhomogeneous half-space the concentration of vertical stress is different than in homogeneous half-space. Modulus of deformability varies continuously with depth. Using of inhomogeneous half-space is also described in papers [12, 13, 14]. The author of paper [14] establishes an equation for shifts in inhomogeneous half-space outside the loaded area in the context of shifts within the loaded area.

The computational model was created using the element SHELL 181 (2D) for slab and using the element SOLID 45 (3D) for the subsoil model. The slab thickness, which was $150 \mathrm{~mm}$, was added to the 2D element SHELL 181. Assignment of specified material properties to the modelled slab and subsoil followed. Material No. 1 was marked concrete with 
modulus of elasticity $\mathrm{E}=34.0 \mathrm{GPa}$ and the Poisson coefficient $\mu=0.2$. The subsoil model was divided into 30 layers. Inhomogeneity of the subsoil was taken into consideration with an increasing modulus of deformability $E_{\text {def,2. Material No. 2-31 was }}$ marked soil with the changing modulus of deformability $E_{\text {def,2 }}$ and the Poisson coefficient $\mu=0.35$. Self weight of soil massif and concrete slab was neglected. Thickness of one layer in subsoil model was $0.2 \mathrm{~m}$. The value of modulus of deformability began on the surface of the subsoil model $E_{\text {def, } 2}=33.86 \mathrm{MPa}$ and its value gradually increased with the deeper layers (Fig. 5) of the formula (1):

$E_{\text {def }}=E_{0} z^{m}$ Fig. 1

$m=\frac{1}{\mu}-2=\frac{1}{0.35}-2=\underline{\underline{0.857}}$

where

$E_{0}$ - modulus of deformability on the upper surface of subsoil model

z - z - coordinate (depth)

$m$ - coefficient addicted on Poisson ratio $\mu$

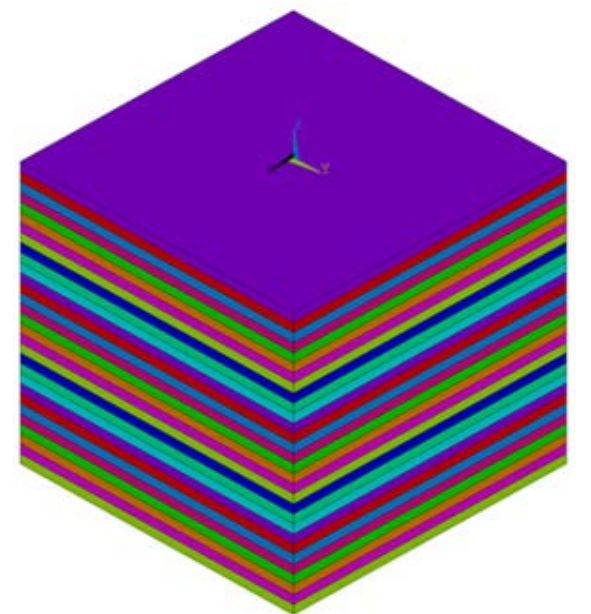

\begin{tabular}{|c|c|c|c|}
\hline$z[m]$ & $E_{\text {def }}[M P a]$ & $z[m]$ & $E_{\text {def }}[M P a]$ \\
\hline 0,0 & 33,86 & 3,0 & 111,11 \\
\hline 0,2 & 39,59 & 3,2 & 115,85 \\
\hline 0,4 & 45,18 & 3,4 & 120,56 \\
\hline 0,6 & 50,66 & 3,6 & 125,25 \\
\hline 0,8 & 56,04 & 3,8 & 129,90 \\
\hline 1,0 & 61,34 & 4,0 & 134,53 \\
\hline 1,2 & 66,56 & 4,2 & 139,12 \\
\hline 1,4 & 71,71 & 4,4 & 143,70 \\
\hline 1,6 & 76,80 & 4,6 & 148,25 \\
\hline 1,8 & 81,84 & 4,8 & 152,78 \\
\hline 2,0 & 86,83 & 5,0 & 157,28 \\
\hline 2,2 & 91,76 & 5,2 & 161,76 \\
\hline 2,4 & 96,66 & 5,4 & 166,23 \\
\hline 2,6 & 101,51 & 5,6 & 170,67 \\
\hline 2,8 & 106,33 & 5,8 & 175,09 \\
\hline 3,0 & 111,11 & 6,0 & 179,50 \\
\hline
\end{tabular}

Fig. 5 Inhomogeneous half-space, modulus of deformability increases with depth
Volumes of the individual layers had different properties according to the table in Fig. 5. 3D finite elements of mesh of subsoil model had dimensions $0.2 \times 0.2 \times 0.2 \mathrm{~m}$. 2D finite elements of mesh of slab model had dimensions $0.1 \times 0.1 \mathrm{~m}$. Both finiteelement meshes were regular.

The load was applied to the nodes in the loaded area with size $200 \times 200 \mathrm{~mm}$. The load value was approximately $525 \mathrm{kN}$ at the moment of sample failure. This value was also implemented in the numerical model. Prestressing was placed in quarters of all sides of slab model. Force in prestressed reinforcement was $100 \mathrm{kN}$ as well as during the experiment (Fig. 6).

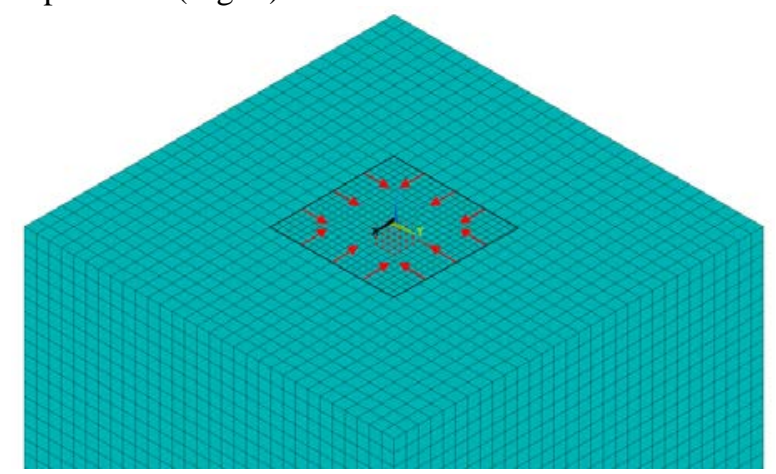

Fig. 6 Prestressing forces introduced into the slab

Creation of mutual contact and definition of the contact area is necessary for the transmission of load effects from the foundation slab to the subsoil. Contact was made using a contact pair TARGE170 and CONTA173. The influence of friction between the slab and the subsoil on the contact area was neglected. Friction coefficient equalled zero. After creating a contact, it is necessary to verify that the normals of both contact surfaces directed against each other (Fig. 7).

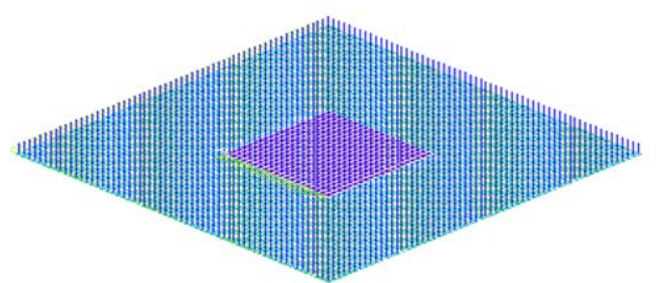

Fig. 7 Contact area made using contact pair TARGE170 and CONTA173

Horizontal nodes shifts in external walls of the subsoil model (No. 2, 3, 4, 5 in Fig. 8) and vertical nodes shifts in the lower base of the subsoil model (No. 6 in Fig. 8) were hindered by boundary conditions.

No boundary conditions hindered the nodes shifts in the upper level of the subsoil model, which represented the terrain (Fig. 8 marked no. 1). 


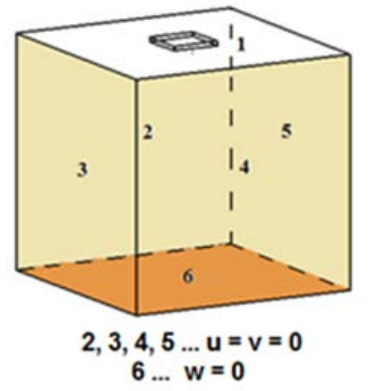

Fig. 8 Boundary conditions in the walls of the subsoil model

Subsoil model with dimensions $6.0 \times 6.0 \times 6.0 \mathrm{~m}$ and with the aforementioned boundary conditions was made on the basis of parametric study [9, 17, 18], and on the basis of the influence mentioned parameters of the 3D model to the total deformation. Numerical modelling of the subsoil-structure interaction is also described in $[4,16]$.

\subsection{The resulting stress and deformations of the post-tensioned concrete slab}

\subsubsection{The resulting deformations of the post- tensioned concrete slab model}

Fig. 9 shows the total vertical deformations of the subsoil model. As expected, the maximum vertical deformation is in the centre of the slab and its value is $4.24 \mathrm{~mm}$. Course and shape of the deformed model is symmetric, thus can also check the accuracy of insertion of symmetrical load, and especially of symmetric prestressing of the slab.

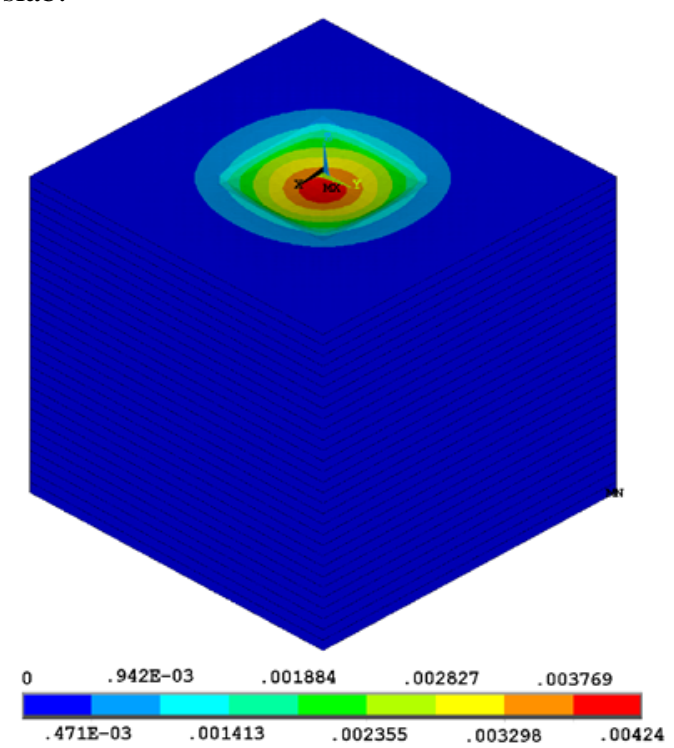

Fig. 9 The resulting vertical deformations [m]

Fig. 10 shows the horizontal deformations of the subsoil model. The course and shape of the deformed model is symmetric (in direction of the coordinate axes $\mathrm{x}$ and $\mathrm{y}$ ) and for presentation of results was chosen only the state of horizontal deformations in direction of the $y$-axis, the deformation $v$. Horizontal deformations in direction of the $\mathrm{x}$-axis have the same course, but rotated about $90^{\circ}$. Deformations in the $y$-direction are totally symmetrical to the beginning of coordinate system situated in the centre of the slab. Horizontal deformations in y-direction toward the slab centre have the same value but the opposite sign, which is evident in Fig. 10. The deformation in the horizontal direction, $\mathrm{x}$ and also $\mathrm{y}$, are affected by the inserted prestress. This is modelled in the level of the prestressed slab model. Fig. 10 shows the locations of the prestressed reinforcement, for clarity in direction of the $\mathrm{y}$-axis. These locations are marked by cross sections A-A, B-B and C-C.

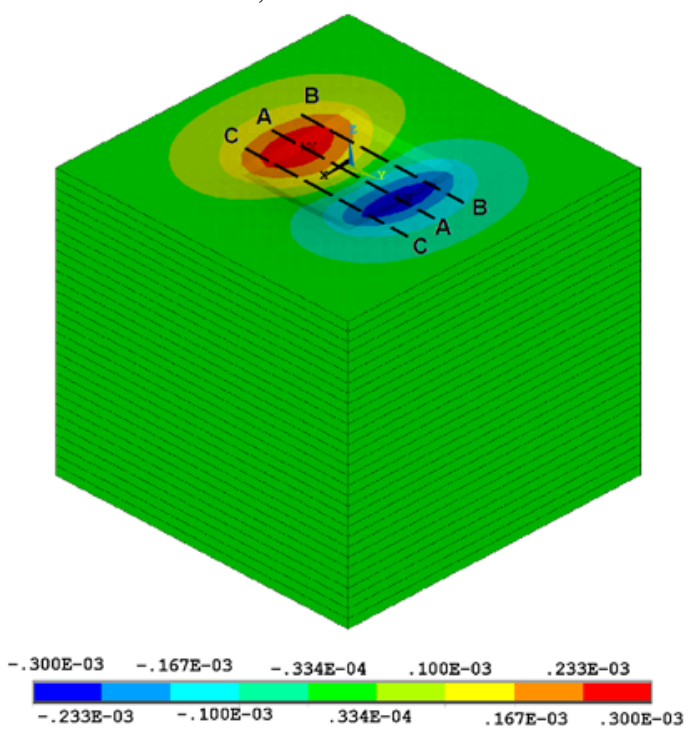

Fig. 10 The resulting horizontal deformations [m]

Horizontal deformations are depicted on the following Fig. 11 in sectional views A-A, B-B, C-C.

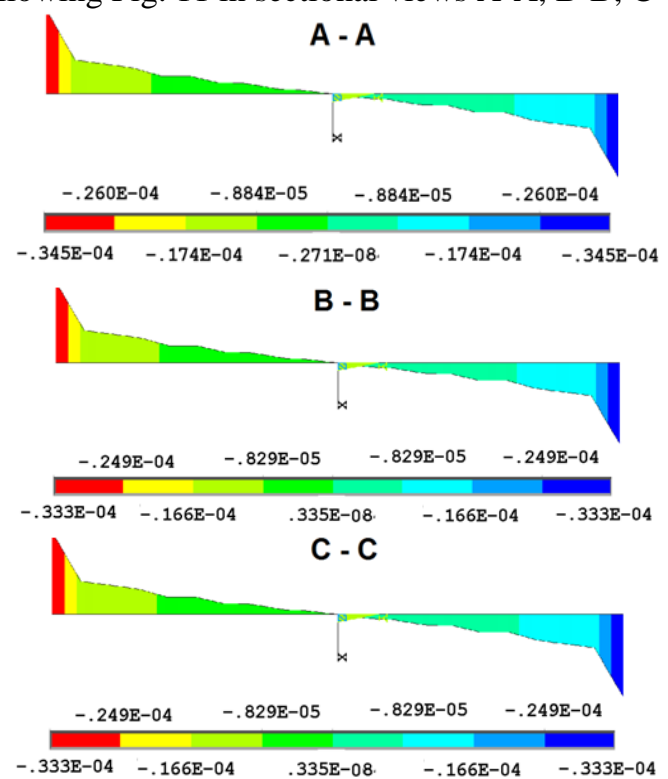

Fig. 11 Horizontal deformations, sectional views [m] 
Influence of the introduced prestressing force to the deformation in the mid-plane of the slab is shown in Fig. 11. Sections shown in the Fig. 11 are conducted in the placement of the prestressing reinforcement. This influence is the greatest under the prestressing reinforcement anchors and gradually fades towards the centre of the slab. Deformations in the $y$-direction are totally symmetrical to the beginning of the coordinate system, which is situated in the centre of the slab. Horizontal deformations in y-direction lead to the slab centre and they have the same value but the opposite sign, which is also visible in Fig. 11.

Horizontal deformations in direction of y-axis in the section A-A are larger than horizontal deformations in sections B-B and C-C. Thereby the assumption was confirmed that a horizontal deformation caused by introduced prestressing forces along the $\mathrm{y}$-axis in the sectional view A-A conducted through the centre of the slab is influenced by forces introduced in the quarter of sides of the slab in sections B-B and C-C. According to the same assumption the horizontal deformations in the sections B-B and C-C are smaller and also symmetrical, which corresponds to the symmetric load and symmetric geometry of the task.

Horizontal deformations in the task without the inserted horizontal prestressing forces were also observed. This observation served mainly to the check of the numerical model and to the monitoring of the influence of introduced prestressing forces. Comparison of horizontal deformations in the y-axis direction in the section A-A with inserted horizontal prestressing forces is shown in the Fig. 12 (above) and without inserted horizontal prestressing forces is shown in the Fig. 12 (below) - this is almost zero.

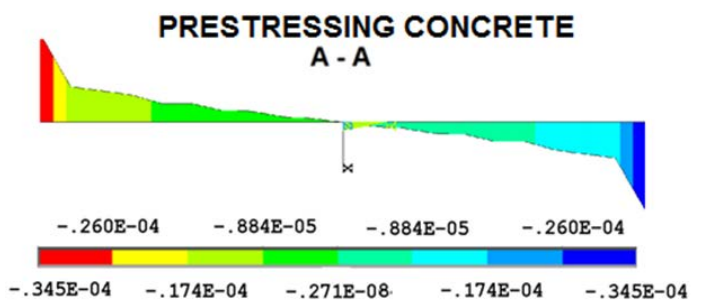

PLAIN CONCRETE

A - A

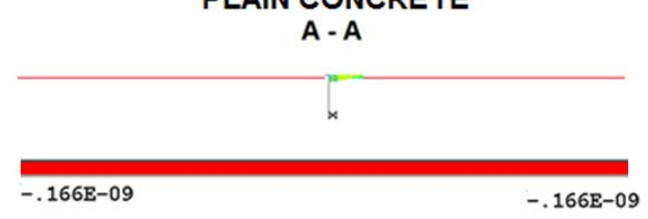

Fig. 12 Comparison of horizontal deformations of prestressing concrete slab and plain concrete slab $[\mathrm{m}]$

\subsubsection{The resulting stress of the post-tensioned} concrete slab

The vertical component of stress $\sigma_{\mathrm{z}}$ in the subsoil is plotted in Fig. 13. Red areas show the greatest tensile stress in the location of the settlement trough of the subsoil (Fig. 14), with values from 650 to 7817.73Pa. Yellow areas show smaller tensile stresses in the subsoil, with values of 0 to $650 \mathrm{~Pa}$.

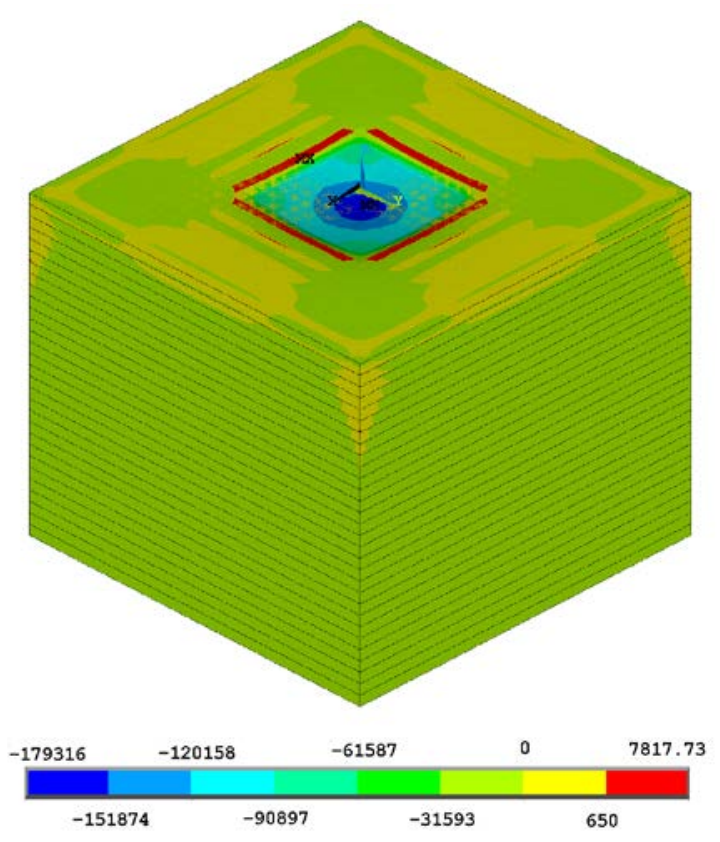

Fig. 13 The vertical component of stress $\sigma_{\mathrm{z}}[\mathrm{Pa}]$

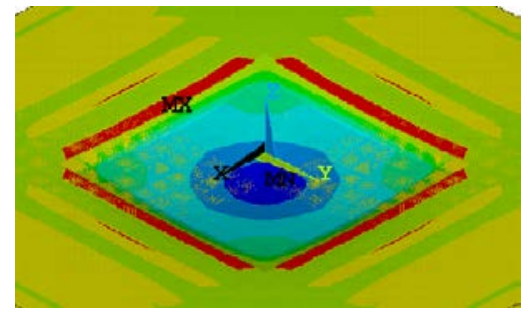

Fig. 14 The detail of the component of stress $\sigma_{\mathrm{z}}$ in the location of the settlement trough $[\mathrm{Pa}]$

Horizontal component of stress $\sigma_{\mathrm{y}}$ is depicted on the following Fig. 15 in sectional views A-A, B-B, $\mathrm{C}-\mathrm{C}$. Influence of the introduced prestressing force to the stress $\sigma_{\mathrm{y}}$ in the mid-plane of the slab is shown in Fig. 15. Sections shown in the Fig. 15 are conducted in the placement of the prestressing reinforcement. Stress $\sigma_{\mathrm{y}}$ gradually increases toward the centre of the slab model due to vertical load applied at the centre of the slab. Introduced forces in the $\mathrm{y}$-axis direction (and the $\mathrm{x}$-axis direction) lead to the middle of the slab. They have the same value of $50 \mathrm{kN}$ and the influence under anchor also evident from Fig. 15. Course of stress $\sigma_{\mathrm{y}}$ depicted in Fig. 15 is the result of vertical loads and also introduced horizontal forces acting simultaneously. 


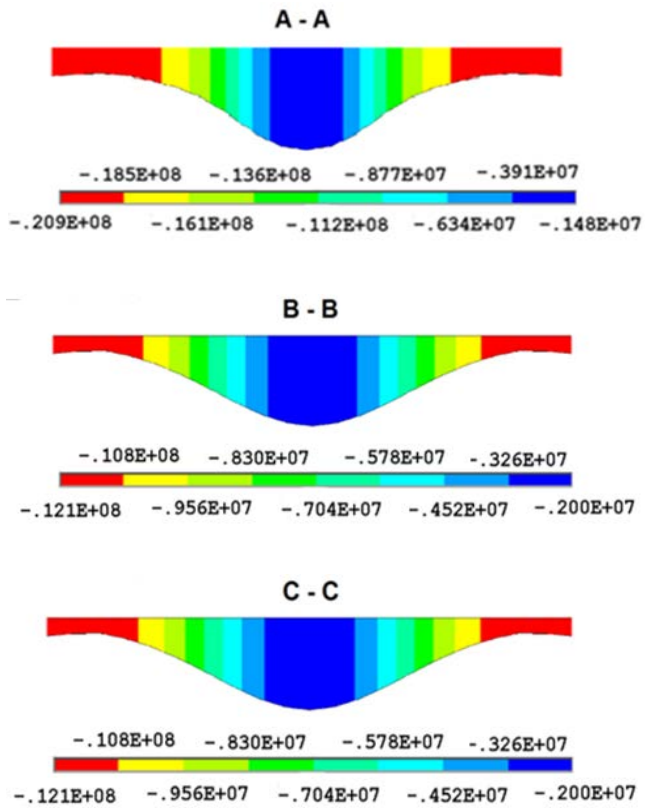

Fig. 15 Horizontal component of stress $\sigma_{\mathrm{y}}$ in sectional views A-A, B-B, C-C, [Pa]

Horizontal component of stress $\sigma_{\mathrm{y}}$ in direction of $\mathrm{y}$-axis in the section A-A is larger than horizontal stress $\sigma_{\mathrm{y}}$ in sections $\mathrm{B}-\mathrm{B}$ and $\mathrm{C}-\mathrm{C}$. Thereby the assumption was confirmed that $\sigma_{y}$ caused by introduced prestressing forces along the y-axis in the sectional view A-A conducted through the centre of the slab is influenced by forces introduced in the quarter of sides of the slab in sections B-B and C-C.

According to the same assumption the horizontal component of stress $\sigma_{\mathrm{y}}$ in the sections B-B and C-C are smaller and also symmetrical, which corresponds to the symmetric load and symmetric geometry of the task. As already mentioned, stress $\sigma_{\mathrm{y}}$ plotted in Fig. 15 is influenced by a vertical load applied perpendicularly to the mid-plane of the slab (caused by hydraulic press) and horizontal loads in a level of the mid-plane of the slab (caused introduced forces characterizing the prestressing).

Fig. 16 shows course of the stress $\sigma_{y}$ for both load cases. Course of the stress $\sigma_{y}$ is plotted in the section A-A. Nevertheless, the principle of the influence of horizontal and vertical acting forces is the same even in the case of sections B-B and C-C, only values are different in comparison with the section A-A. The course of total horizontal component of stress $\sigma_{\mathrm{y}}$ is the sum of two partial load cases of forces acting in the direction of y-axis $\left(\Sigma \mathrm{F}_{\mathrm{y}}\right)$ and the $\mathrm{z}$-axis $\left(\Sigma \mathrm{F}_{\mathrm{z}}\right)$.

\section{ACKNOWLEDGEMENTS}

This outcome has been achieved with the financial support of the GACR - Czech Science Foundation, project No.16-08937S "State of stress and strain of fiber reinforced composites in interaction with the soil environment“.

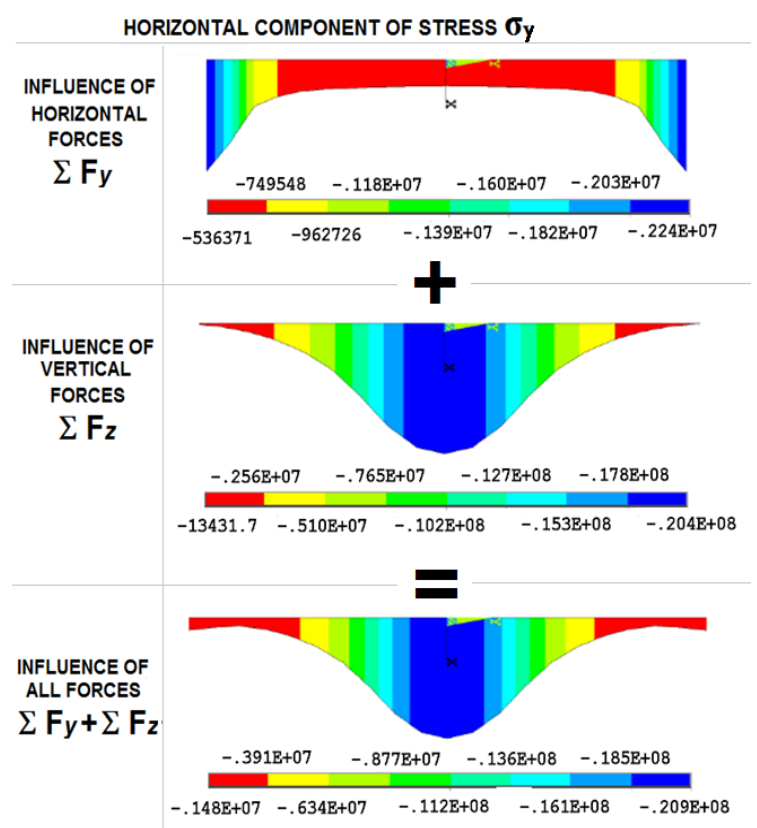

Fig. 16 Horizontal component of stress $\sigma_{y}$ in the section A-A

\section{CONCLUSION}

Numerical analysis of the interaction of prestressed concrete slab and subsoil was carried out using an inhomogeneous half-space in which the value of the modulus of deformability increases with depth, and can be relatively well capture soil behavior. Modulus of deformability increases with subsoil depth. Experimental value of deflection in the middle of slab measured during test was $17.8 \mathrm{~mm}$. Result from numerical model was $4.24 \mathrm{~mm}$. Nevertheless value $17.8 \mathrm{~mm}$ was determined for cracked concrete. Deflection in the middle of concrete slab was about $5 \mathrm{~mm}$ during the first crack initiation. It is only $18 \%$ difference between numerical and tested values. The numerical model also reflected the effects of prestressing and the influence of prestressing on deformation and stress. While monitoring the effect of prestressing and its consideration in the numerical model, the emphasis was mainly on components of stress and strain in the plane of the modelled slab. However, the prestressing increases the rigidity of the element and thus has an influence during the transfer of the vertical load components. In consequence of the increase of rigidity due to the prestressing, smaller vertical deflections of the slab than in the case of prestressed slabs were calculated.

\section{REFERENCES}

[1] R. Halvonik, J., Fillo, “The Maximum Punching Shear Resistance of Flat Slabs, Procedia Engineering”, vol.: 65, 2013, pp 376-381, ISSN 1877 - 7058, 
[2] M. Aboutalebi, A. Alani, J. Rizzuto, D. Beckett, "Structural behaviour and deformation patterns in loaded plain concrete ground-supported slabs”. Structural Concrete. 2014, vol. 15, issue. 1, pp. 81-93. ISSN 1464-4177.

[3] T. Clément, A.P. Ramos, M.F. Ruiz, A. Muttoni, "Influence of prestressing on the punching strength of post-tensioned slabs", Engineering Structure, vol. 72, pp. 56-69 (14 p), ISSN: 01410296, 2014

[4] K. Frydrysek, R. Janco, H. Gondek, "Solutions of Beams, Frames and 3D Structures on Elastic Foundation Using FEM”, International Journal of Mechanics, Issue 4, Vol. 7, p. 362-369, 2013.

[5] P. Mynarcik, "The Subsidence Analysis of Experimental Post-tensioned Concrete Slab Model in the Course of the Static Load Test”, Applied Mechanics and Materials, vol. 744 746, pp. 1556-1559 (4 p), Trans Tech Publications, Switzerland, 2015.

[6] A. Alani, M. Aboutalebi, "Analysis of the subgrade stiffness effect on the behaviour of ground-supported concrete slabs" Structural Concrete, Issue 13, Volume 2, pages 102-108, DOI: 10.1002/suco.201100043, 2012.

[7] R. Cajka, R. Fojtik, "Development of Temperature and Stress during Foundation Slab Concreting of National Supercomputer Centre IT4”, Procedia Engineering, vol. 65, 2013, pp. 230-235 (6 p), ISSN 1877-7058,

[8] R. Cajka, K. Burkovic, V. Buchta, "Foundation Slab in Interaction with Subsoil”, Advanced Materials Research, Vols. 838-841, pp. 375-380, Trans Tech Publications, Switzerland, 2014.

[9] R. Cajka, J. Labudkova, „Influence of parameters of a 3D numerical model on deformation arising in interaction of a foundation structure and subsoil“", (COSTMA '13), Budapest, Hungary, 2013.

[10]R. Cajka, P. Mateckova, ”Comparison of calculating methods and consequent carrying capacities of pre-stressed precast concrete roof purlin”, in proceedings of First International Workshop "Design of Concrete Structures using EN 1992-1-1, Prague, 2010.

[11] M. Janulikova, R. Cajka, P. Mateckova, V. Buchta, "Laboratory Testing of Asphalt Belts Rheological Properties Exposed to Shear Loads”, Transactions of the VŠB - Technical University of Ostrava, Civil Engineering Series, vol. XII, iss. 2, pp. 59-66 (8 p).

[12] K. Zhou , W. W. Chen, L. M. Keer, X. Ai, K. Sawamiphakdi, P. Glaws, Q. J. Wang, "Multiple 3D inhomogeneous inclusions in a half space under contact loading”, Mechanics of Materials, Vol. 43, Issue 8, Pages 444-457, 2011.

[13] V. I. Fabrikant, T. S. Sankar, „On contact problems in an inhomogeneous half-space“, International Journal of Solids and Structures, Volume 20, Issue 2, Pages 159-166, 1984.

[14] K. Zhou, W. W. Chen, L. M. Keer, X. Ai, K. Sawamiphakdi, P. Glaws, Q. J. Wang, „Multiple
3D inhomogeneous inclusions in a half space under contact loading“, Mechanics of Materials, Vol- 43, Issue 8, pp.444-457, 2011.

[15] R. Cajka, V. Krivy, D. Sekanina, "Design and Development of a Testing Device for Experimental Measurements of Foundation Slabs on the Subsoil”, Transactions of the VŠB - Technical University of Ostrava, Civil Engineering Series, vol. XI, iss. 1, pp. 1-6, ISSN 1804-4824, ISBN 978-80-248-2332-4.

[16]R. Cajka, “Analytical derivation of friction parameters for FEM calculation of the state of stress in foundation structures on undermined territories”, Acta Montanistica Slovaca, vol. 18, iss. 4, pp. 254-261 (8 p), ISSN: 13351788, 2013.

[17]R. Cajka, J. Labudkova, „Dependence of deformation of a plate on the subsoil in relation to the parameters of the 3D model“", International Journal of Mechanics, Volume 8, Pages 208-215, 2014, ISSN: 1998-4448.

[18] J. Labudkova, R. Cajka, "Comparsion of Measured Displacement of the Plate in Interaction with the Subsoil and the Results of 3D Numerical Model”, Advanced Material Research, vol. 1020, pp. 204-209 (6 p), Trans Tech Publications, Switzerland, ISSN (Online) 1662-8985, ISSN (Print) 1022-6680, 2014.

[19] Cajka, K. Burkovic, V. Buchta, R. Fojtik, "Experimental soil - Concrete plate interaction test and numerical models”, Key Engineering Materials, vol. 577-578, pp. 33-36 (4 p), Trans Tech Publications, Switzerland, 2014.

[20]Bin Tian, Rui Li, Yang Zhong, “Integral transform solutions to the bending problems of moderately thick rectangular plates with all edges free resting on elastic foundations“, Applied Mathematical Modelling, Vol. 39, Issue 1, 2015, pp. 128-136.

[21] Shukla, S.J., Desai, A.K., Solanki, C.H., “A behavioural study of dynamic soil structure interaction for piled raft foundation with variable sub soils by time history fem model”, International Journal of Geomate, Vol. 8, Iss.2, 2015, pp. 1288-1292, 2015.

[22]Benadla, Z., Hamdaoui, K., Aissaoui, S., Baouch, A., "Influence of the soil-structure interaction on the seismic behavior of buildings on shallow foundations", International Journal of GEOMATE, Vol. 6, Iss. 1, pp. 811-816, 2014.

International Journal of GEOMATE, July, 2016, Vol. 11, Issue 23, pp. 2116-2122.

MS No. 1208 received on July 31, 2015 and reviewed under GEOMATE publication policies.

Copyright (C) 2016, Int. J. of GEOMATE. All rights reserved, including the making of copies unless permission is obtained from the copyright proprietors. Pertinent discussion including authors' closure, if any, will be published in March 2017 if the discussion is received by Sept. 2016.

Corresponding Author: Radim Cajka 
International Journal of GEOMATE, July, 2016, Vol. 11, Issue 23, pp. 2116-2122 